\title{
Laryngealized Phonation ('Vocal Fry') in Speakers of New Zealand English: Two Contrastive Case Studies
}

\author{
Eva Maria Leuf \\ Department of Languages, Frankfurt School of Finance and Management, Frankfurt am Main, Germany
}

Email address:

emluef@dozent.frankfurt-school.de

\section{To cite this article:}

Eva Maria Leuf. Laryngealized Phonation ('Vocal Fry') in Speakers of New Zealand English: Two Contrastive Case Studies. International Journal of Language and Linguistics. Vol. 4, No. 3, 2016, pp. 128-132. doi: 10.11648/j.jill.20160403.16

Received: April 11, 2016; Accepted: May 4, 2016; Published: May 20, 2016

\begin{abstract}
Laryngealized phonation, also known as glottalized phonation or vocal fry, has recently received increased research attention as it represents a socio-phonetic marker that characterizes young urban women's speech. So far, all studies have focussed on speakers of American English and it has been shown that college-aged female students make use of laryngealized phonation in particular to mark the end of sentences. The present study is the first to investigate speakers of New Zealand English to determine whether laryngealized phonation is also a feature of the New Zealand variant of English and to identify possible functional aspects of laryngealized phonation.
\end{abstract}

Keywords: Laryngealized Phonation, Glottalized Phonation, New Zealand English, Narrative Discourse

\section{Introduction}

Laryngealized phonation is characterized by vocal fold vibration at a very low frequency caused by strong adduction and weak longitudinal tension of the vocal folds [1, 2]. The resulting thickness of the vocal folds, which may additionally come into contact with the false vocal folds, results in low tension and heavy vibrating mass that are responsible for the slower and irregular vibration [1]. In comparison to normal phonation, the subglottal pressure and the glottal airflow are lowered. Laryngealized phonation is produced at a flow rate of 12-20 ccls and pulses are produced in a frequency range from 25 to 50 Hertz [3]. Also known as creaky phonation, glottal phonation, pulse phonation or vocal fry [see 4], laryngealized phonation has traditionally been associated with speech pathology [5,6]. Recently, laryngealized phonation has been noted to become more common and "fashionable" among young women in the United States [7, 8], similar to the use of the quotative like or uptalk [9]. Among young female speakers, typically the end of sentences is marked by laryngealized phonation, resulting in particular speech patterns. There is disagreement on whether laryngealized speech in young American women is perceived negatively or positively by listeners within their linguistic community. Anderson et al. [10] report that women using laryngealized speech face disadvantages in competitive social situations, such as job interviews. A similar study by Yuasa (2010), however, indicates that laryngealized phonation is perceived in positive terms indicating social upward mobility in young urban women. Perception of laryngealized voice may depend on the demographic of the listeners: young females tend to evaluate laryngealized speech more favorably (see Yuasa, 2010, study), whereas older people and men tend to perceive it in more negative terms (see Anderson et al., 2014, study).

Concerning the use of non-pathological laryngealized phonation, research efforts have primarily focussed on female American speakers. To date, not much is known about the use of laryngealized phonation in male speakers and speakers of English variants aside from American Standard English. The present study presents a preliminary overview and analysis of the use of laryngealized phonation in male and female speakers of New Zealand English during a free narration task. The present study will explore how frequent laryngealized phonation occurs in speakers of New Zealand English and whether some word classes are more often affected by laryngealized phonation. Furthermore it will be explored in which sentence position laryngealized phonation primarily occurs and whether if affects all sounds or only a part of the sounds that make up a word. Finally the question of whether laryngealization is restricted to one word of an utterance or whether it extends over multiple consecutive 
words will be investigated.

Laryngealized phonation may be a more wide-spread vocal phenomenon among young adults in the English-speaking world. Detailled studies of the function of laryngealization can provide important insights into the dynamics of sociophonetic trends and help understand how vocality and phonation modes can become connotated with novel functions within linguistic communities.

\section{Methods}

Participants were two native speakers of New Zealand English (accents of the northern island, greater area Auckland), one female and one male, both aged between 22 and 25 years. One recording was collected from each participant. Participants were asked to read a fairy tale and to recall and freely narrate the story afterwards. The recording sessions took place in an office at the University of Auckland in 2006. The speakers moved freely and were able to express themselves in a natural, conversational style throughout the recording. Audio-recordings were collected with a Sony MZR35 Mini-Disc device (plus Sony MD discs) and a Sony ECM-707 directional microphone. The audio stream was segmented with the software PRAAT and each word was manually annotated. In addition, each word was classified as one of the following word classes: noun, verb, adjective, adverb, pronoun, preposition, conjunction, determiner or interjection. After annotation with PRAAT, laryngealized passages were extracted, noting whether laryngealization occurred on single sounds or syllables or extended across the entire word. It is common practise to first identify laryngealized speech by ear and then confirm the results through spectrographic visualization [11, 12]. In particular, long glottal cycles, a decrease (or disappearance) of fundamental frequency and wave sound shape are indicators of laryngealized speech. A laryngealized passage was defined as uninterrupted by passages of modal phonation.

There are different metholodogies to account for laryngealized phonation. One may count syllables produced with laryngealization and relate them to the totality of syllables used by a particular speaker [13]. Alternatively, words with and without laryngealized phonation may be set in relation by calculating a ratio $[7,14]$. In addition, it is crucial to account for single sounds as laryngealized phonation primarily acts on the sound level and words may only be partly laryngealized. The present study annotated words and single sounds as laryngealized or not and calculated a ratio between words pronounced with laryngealized phonation and those without. Due to the preliminary nature of the study, a small sample size was chosen and only descriptive statistics will be provided.

\section{Results}

A total of 869 words were analyzed (female speaker: 536, male speaker: 333) and the annotation revealed 95 occurrences of laryngealized phonation for the two speakers pooled together (female speaker: $66=12.3 \%$ of her words, male speaker: $29=8.7 \%$ of his words). The occurrences showed the following distribution according to word class and sex of the speakers (see figure 1):

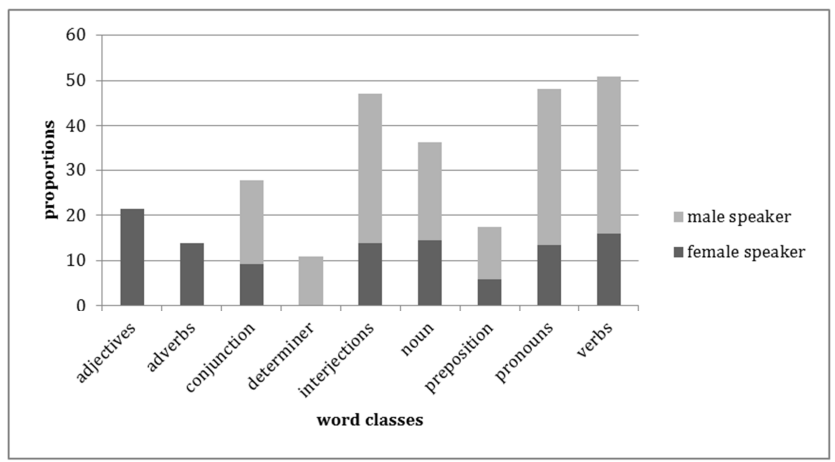

Figure 1. Proportions of words pronounced with laryngeal phonation according to word classes.

Word classes that were most commonly pronounced with laryngealized phonation were interjections, pronouns and verbs. In particular the male speaker produced a substantial proportion of his interjections, pronouns and verbs with laryngealization. The female speaker pronounced a large part of her adjectives and adverbs with laryngealized phonation, both of which were never laryngealized by the male speaker. Determiners, on the other hand, were phonated with laryngealization only by the male speaker.

Concerning the occurrence of laryngeal phonation within the sentence structure, differences were recorded between the two speakers (see figure 2).

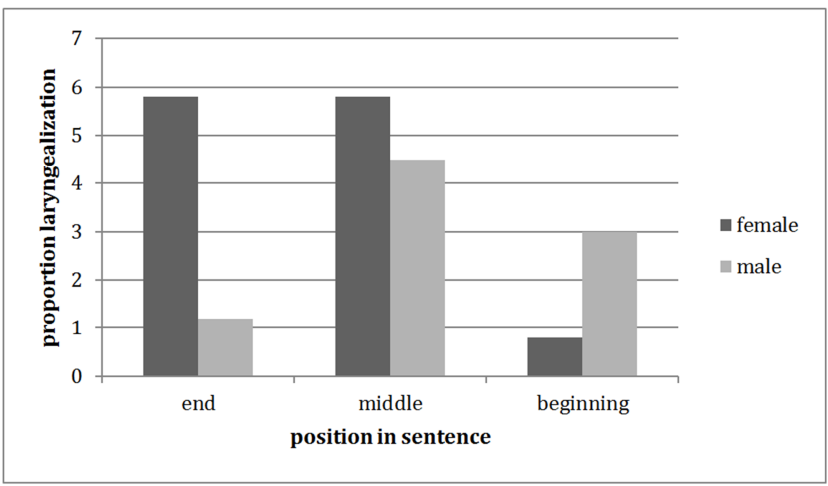

Figure 2. Distribution of laryngealized words within sentences.

The female speaker most often laryngealized words that marked the end of a sentence, while the male speaker frequently produced laryngealized voice on words that started sentences. Both had an equal amount of laryngealized words that occurred on any position in the middle of sentences (between the first and the last word).

In general, the male speaker used laryngealized phonation more often for the entirety of a word, whereas the female speaker commonly only laryngealized parts of a word (most often vowels). Table 1 shows the percentage of whole-word versus part-of-word laryngealized phonation for the two speakers. 
Table 1. Proportion of words with laryngeal phonation across all sounds of a word (whole) or only on a part of the sounds that make up the word (part).

\begin{tabular}{lll}
\hline Word & Female speaker & Male speaker \\
\hline whole & 7,6 & 7,8 \\
part & 4,7 & 1 \\
\hline
\end{tabular}

The spectrogram in figure 3 illustrates how only part of a word can be affected by laryngealization.

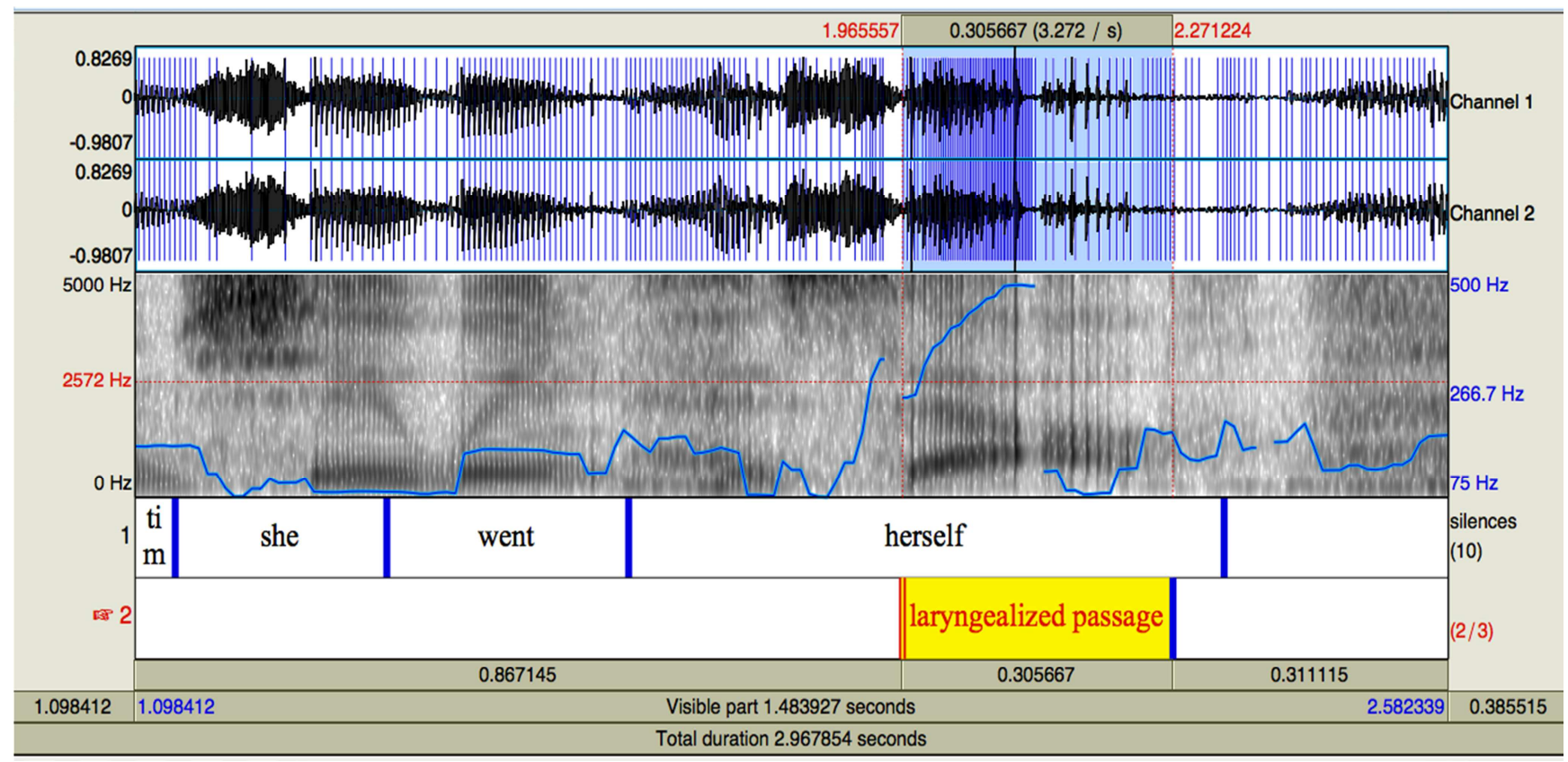

Figure 3. Example of part-of-word laryngealization.

At times the speakers produced not just one word with laryngealized phonation but extended the laryngealization to the consecutive word (see figure 4). This occurred in $4.7 \%$ of all laryngealization instances in the female speaker and in $1.8 \%$ of the instances in the male speaker.

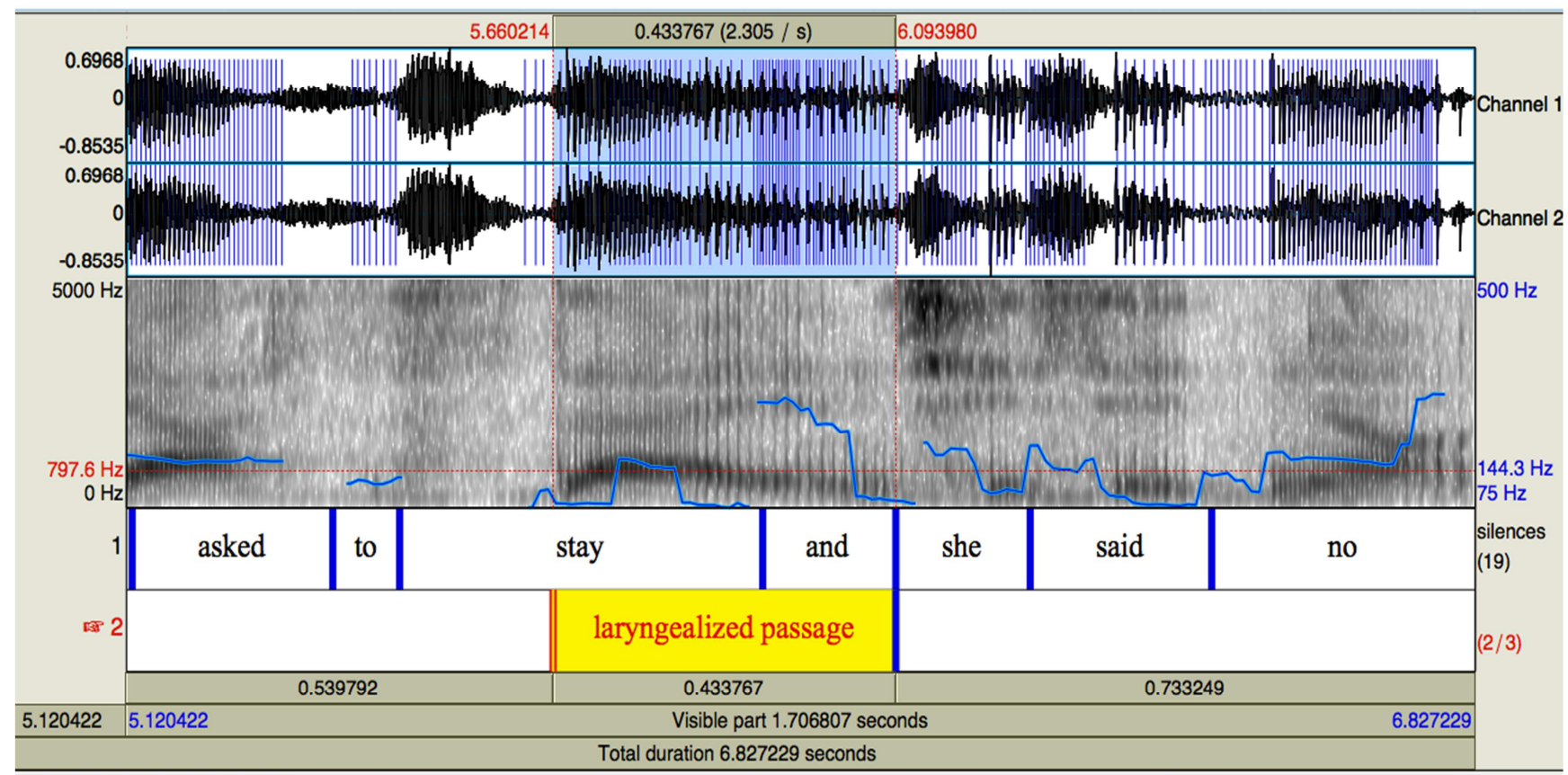

Figure 4. Laryngealized phonation on consecutive words. 


\section{Discussion}

The results of the present study demonstrate that laryngealized phonation is used by young speakers of New Zealand English during narrative discourse. It was shown that the female speaker used laryngealized phonation more frequently than the male speaker, which parallels previous findings from speakers of American English [7, 8]. The driving forces behind the use of laryngealization in young people may be an attempt to sound more 'masculine' by lowering the voice and thus evoke the perception of being more authoritative and serious [10]. The motivation to do so may be greater in young women than in young men, resulting in higher rates of laryngealization for women's voices.

The two investigated speakers different with regards to word classes that were most frequently pronounced with laryngealized voice. While the female speaker exclusively laryngealized adjectives and adverbs, the male speaker laryngealized determiners. This general difference may relate to another finding of the present study: the male speaker frequently laryngealized words at the beginning of his sentences (e.g. and, but) but the female speaker more commonly laryngealized words that ended her sentences. One explanation for this may be the different distribution of word classes within a sentence that may result in the differences in laryngealization of word classes that were observed. Studies on female American speakers showed that laryngealization primarily occurred at the end of sentences (or phrases), presumably as a substitute for the dropping of fundamental frequency [8]. This trend was mirrored by the female speaker in the present study, however, not by the male speaker. It is possible that the male speaker used laryngealized phonation for different functions: laryngealization at the start of a sentence may ensure that the listener's attention is attracted before an utterance begins and may function to enhance perceptability.

The parts of words that were laryngealized also differed between the two speakers. The female speaker produced a part of her overall laryngealization events on only parts of a word, whereas the male speaker predominantly laryngealized his entire words. This may again be related to the fact that different word classes were preferentially laryngealized by the two speakers: determiners, pronouns, and interjections, which were frequently laryngealized by the male speaker, may generally be shorter words and have fewer sounds than, for instance, adjectives and adverbs, which were frequently laryngealized by the female speaker. It may be easier to uphold continuous laryngealization on shorter words consisting of fewer sounds as opposed to longer words, such as beautiful, which are more difficult to laryngealize from beginning to end in articulatory terms.

Finally, the female speaker more frequently laryngealized groups of neighboring words, such as in (laryngealized passages underlined):

"he saw that she was going into a house"

"she said no"
This phenomenon was most commonly observed at sentence boundaries. The male speaker, on the other hand, mostly targeted individual words which were pronounced with laryngealized phonation and rarely extended the laryngealization to the following word, as for instance in

"and he comes across a den of murderers"

A possible explanation may be that laryngealization exerted a contagious effect in the female speaker and was prolonged over the following words as well. This may be aided by falling intonation toward the end of sentences (where laryngealization frequently occurred). Alternatively, laryngealized phonation across mulitple neighboring words (or phrases, such as of course) may hold a prosodic or syntactic function by indicating syntactic or phrasal boundaries.

In sum, the present study adds to the small body of research on laryngealized phonation in English by demonstrating that the phenomenon of laryngealization is also found in young speakers of New Zealand English. Differences were uncovered in how two speakers make use of laryngealization during narrative discourse. These differences may be idiosyncratic or could be related to a general difference between the sexes. The small sample size of two speakers does not allow definitive conclusions as to the effect of sex on the results of the study, however, future studies should focus on a possible sex-related difference in the use of laryngealized phonation in New Zealand speakers. The present study focussed on the use of laryngealized phonation in free story telling. This fact may influence the findings and it is well conveivable that a different type of discourse may show different patterns of laryngealization in speakers of New Zealand English. It will be important for future studies to elucidate in more detail the usage patterns of laryngealized phonation in larger populations of English speakers of different linguistic communities.

\section{References}

[1] H. Eckert, J. Laver, Menschen und ihre Stimmen. (Beltz Psychologie Verlags Union, Weinheim, 1994).

[2] L. Redi, S. Shattuck-Hufnagel, Variation in the realization of glottalization in normal speakers. J Phonetics 29, 407 (2001).

[3] D. G. Childers, C. K. Lee, Vocal quality factors: Analysis, synthesis, and perception. J Acoust Soc Am 90, 2394 (1991).

[4] C. A. Klofstad, R. C. Anderson, S. Peters, Sounds like a winner: Voice pitch influences perception of leadership capacity in both men and women. Proc R Soc B 297, 2698 (2012).

[5] H. Hollien, P. Moore, R. W. Wendahl, J. F. Michel, On the nature of vocal fry. J Speech Hear Res 9, 245 (1966).

[6] H. Hollien, R. W. Wendahl, Perceptual study of vocal fry. $J$ Acoust Soc Am 3, 506 (1968).

[7] I. P. Yuasa, Creaky voice: A new feminine voice quality for young urban-oriented upwardly mobile America women? $\mathrm{Am}$ Speech 85, 315 (2010). 
[8] L. Wolk, N. B. Abdelli-Beruh, D. Slavin, Habitual use of vocal fry in young adult female speakers. $J$ Voice 26 , e111 (2012).

[9] E. Jacewicz, R. A. Fox, C. O'Neill, J. Salmons, Articulation rate across dialect, age, and gender. Lang Var Change 21, 233 (2009).

[10] R. C. Anderson, C. A. Klofstad, W. J. Mayew, M. Venkatachalam, Vocal fry may undermine the success of young women in the labor market. PLoS One, (2014).

[11] A. Benoist-Lucy, C. Pillot-Loiseau, paper presented at the Interspeech 2013, Lyon, France, August 25-29 20132013.
[12] J. Kane, T. Drugman, C. Gobl, Improved automatic detection of creak. Computer Speech and Language 27, 1028 (2012).

[13] C. Henton, A. Bladon, in Language, speech and mind: Studies in honour of Victoria A. Fromkin, L. Hyman, C. N. Li, Eds. (Routeledge, London, 1988).

[14] R. J. Podesva, Phonation type as a stylistic variable: The use of falsetto in constructing a persona. Journal of Sociolinguistics 11, 478 (2007). 